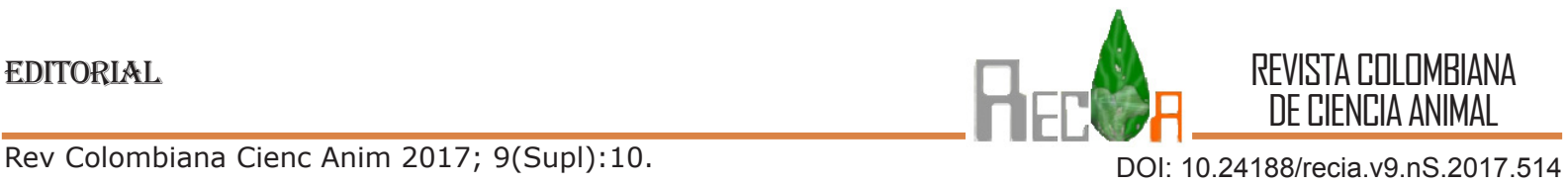

\title{
Cambio climático y ciudades sostenibles
}

\author{
Climatic change and sustainable cities
}

De la ossa V, Jaime ${ }^{1}$ Ph.D, Montes-Vergara, Donicer² Ph.D, Pérez-Cordero, Alexander² Ph.D.

${ }^{1}$ Editor Revista Colombiana de Ciencia Animal RECIA, Universidad de Sucre, Colombia. ${ }^{2}$ Editor Asociado Revista Colombiana de Ciencia Animal RECIA, Universidad de Sucre, Colombia.

El cambio climático es considerado como uno de los principales desafíos para el desarrollo. La comunidad cientifica ha reiterado que el cambio climático antropogénico, aquel causado por actividades humanas, tales como: transporte urbano, producción de energía, deforestación, entre otras, viene ocurriendo a lo largo del último siglo, aumentando la temperatura de la tierra y en consecuencia la probabilidad e intensidad de los eventos climáticos, se tienen hoy incrementos en precipitaciones, extensas inundaciones y prolongadas sequías, por mencionar solo algunos de los impactos negativos. Se deben tomar medidas para aumentar la resiliencia, de lo contario se prevé que el impacto que tendrá el cambio climático será devastador, especialmente en las áreas urbanas, En tal sentido, es importante reconocer que las ciudades son puntos críticos de vulnerabilidad. (https://blogs.iadb.org/ciudadessostenibles/2017/03/28/ resiliencia-areas-urbanas-lecciones-paramaribo/ ) y deben tener propuestas científicas, técnicas y políticas para la adaptación al cambio climático, enfatizando en las medidas de mitigación como una estrategia vital que no da espera.

La situación, con consecuencias negativas por cierto, requiere con urgencia un cambio de paradigma, se debe adoptar un modelo de planificación en la gestión urbana que incorpore la adaptación al cambio climático como una prioridad y que como tal sea atendido desde perspectivas modernas y conservacionistas activas, siguiendo las recomendaciones científicas de mayor avance en esta materia sin descuidar el bienestar de la comunidad y la soberanía de sus recursos naturales.

Señala de forma acertada FINDETER (http://www.findeter.gov.co/ninos/publicaciones/_que_es_una_ciudad_ sostenible_pub), en cuanto a la dimensión de sostenibilidad ambiental y cambio climático, que una ciūadad sostenible debe atender de manera prioritaria el manejo de los recursos naturales, la mitigación de gases efecto invernadero y otras formas de contaminación, igualmente se debe enfocar en la a la mitigación y adaptación a los efectos de cambio climático. En cuanto a la dimensión de desarrollo urbano sostenible, una ciudad sostenible debe controlar su crecimiento y promover la provisión de un hábitat adecuado para sus ciudadanos, además de promover el transporte y la movilidad urbana sostenible. En cuanto a la dimensión de sostenibilidad económica y social, una ciudad sostenible debe promover un desarrollo económico local y el suministro de servicios sociales de calidad. Asimismo, la ciudad debe promover niveles adecuados de seguridad ciudadana. Finalmente, en materia de la dimensión fiscal debe avanzar en la aplicación de mecanismos adecuados de buen gobierno, de manejo adecuado de sus ingresos y del gasto público, así como de manejo adecuado de la deuda y otras obligaciones fiscales.

Este panorama alentador y visionario ofrece las mejores posibilidades de desarrollo sostenible para nuestra ciudad capital, Sincelejo, y su hermana ciudad de Corozal, las que por sus características ambientales, económicas y sociales están en grave riesgo por acción del cambio climático y sus consecuencias. Bienvenido el programa de ciudades sostenibles y los mejores augurios para que se convierta en una política regional transcendente. 